\title{
Tradições de história global na América Latina e no Caribe
}

\section{Traditions of Global History in Latin America and the Caribbean}

\author{
Rafael Marquese \\ marquese@usp.br \\ Professor Associado \\ Universidade de São Paulo \\ Av. Prof. Luciano Gualberto, 315 - Cidade Universitária \\ 05508-900 - São Paulo - SP \\ Brasil
}

\section{João Paulo Pimenta}

jgarrido.pimenta@gmail.com

Professor Associado

Universidade de São Paulo

Av. Prof. Luciano Gualberto, 315 - Cidade Universitária

05508-900 - São Paulo - SP

Brasil

\section{Resumo}

Neste artigo é feito um apanhado crítico de autores e correntes historiográficas que, nos séculos XIX e XIX, estiveram voltados para a história da América Latina e do Caribe e que de muitas maneiras podem, efetivamente, ser considerados representantes do que hoje se reconhece como uma chamada história global. Com isso, pretende-se matizar e relativizar os afãs renovadores daqueles historiadores que atualmente se identificam com tal postura, bem como valorizar a importância de olhares abrangentes e articulados sobre a história do continente americano.

\section{Palavras-chave}

História global; Historiografia latino-americana; Historiografia caribenha.

\begin{abstract}
This article presents a critical overview of $20^{\text {th }}$-century authors and historiographical trends on the history of Latin America and the Caribbean, which, in different ways, can be effectively considered representative of what is nowadays known as global history. With this effort, we intend to put in perspective and cast a light of relativity on the aspirations of renewal by historians who currently affirm their identity in terms of such stance and its potential innovations, and to emphasize the importance of wide-ranging and well-articulated views of the history of the American continent.
\end{abstract}

Keywords

Global History; Latin American historiography; Caribbean historiography.

Recebido em: 3/5/2014

Aprovado em: 28/7/2014 


\section{Introdução: o século XIX e as primeiras décadas do $\mathbf{X X}$}

Em 24 de fevereiro de 1821, o comandante militar Agustín de Iturbide, protagonista da cena política do Vice-Reino de Nova Espanha, anunciava o famoso Plan de Iguala, por meio do qual se desenhava a independência daquela parte do Império Espanhol e a criação do Império Mexicano. Suas palavras iniciais, muito significativamente, dirigiam-se aos "Americanos! Sob cujo nome compreendo não apenas os nascidos na América, mas também aos europeus, africanos e asiáticos que nela residem" (ROMERO; ROMERO 1997, p. 283).

Nas últimas décadas do século XVIII e nas primeiras do século XIX, os processos de crise e parcial dissolução dos impérios ibéricos na América estiveram embasados em ideias, análises, discursos, conceitos e vocabulários que, como os que foram empregados por Iturbide, apresentavam os grandes acontecimentos da época, dos quais resultaria a criação de quase duas dezenas de Estados nacionais independentes e soberanos, como um capítulo fundamental da história da humanidade; uma história de americanos, europeus, africanos e asiáticos e que, para todos os efeitos, confundia-se com uma história concebida como de muitas partes do mundo relacionadas entre si e ao mesmo tempo. Um entendimento desse tipo era comum e generalizado já naquela passagem de século, tornando-se ainda mais comum nas primeiras décadas a ela subsequentes. Ele se configura como um fenômeno em si, passível de ser estudado como dimensão relevante da própria história das ideias da época. Mas tal entendimento também forneceria poderoso argumento analítico aos que, mais adiante, dedicar-se-iam a estudar como aqueles impérios desapareceram e como novas sociedades e organismos políticos tomaram seu lugar.

Os historiadores, contudo, nem sempre defenderam que as histórias de seus respectivos países ou das realidades específicas nelas inscritas eram parte de uma história mais geral que, supostamente as envolveria. O século XIX observou por toda a parte, pari passu ao surgimento de Estados nacionais modernos, a emergência de narrativas sobre o passado a desenharem as supostas singularidades - eventualmente, também as superioridades - de cada um desses Estados e das sociedades a eles correspondentes. Mesmo assim, o triunfo das histórias nacionais ensejava uma relação comparativa: cada uma delas só podia ser considerada única em relação a outras, forçosamente observadas. No entanto, a despeito de sua ampla prevalência, tais narrativas jamais impediram o surgimento de posturas críticas que, deliberadamente, expandiram os horizontes espaciais de suas observações, fosse em direção a uma história de vários países do continente americano, do próprio continente em si, ou de partes dele como integradas com outras partes do mundo.

Consideram-se aqui tais posturas como representantes pioneiras de uma atitude historiográfica que, hoje, deveria ser tida como menos inovadora do que muitos de seus atuais praticantes parecem dispostos a reconhecer. Nesta segunda década do século XXI, a história do mundo ibero-americano continua a possibilitar o exercício de uma chamada história global, a valorizar realidades e fenômenos específicos como partes de realidades amplas e a conduzir seus estudiosos por caminhos que vão muito além de tempos e espaços nacionais 
específicos e isolados uns dos outros. Do fato de que a relatividade do ponto de observação do historiador se encarrega de renovar constantemente formas de concepção de seu objeto, desprende-se um problema, a ser apontado nas páginas seguintes: em que medida algumas variantes do que atualmente se classifica como história global - e muito comumente reivindicadas mais como superação do que como renovação de formas de escrita da história anteriores já não foram praticadas antes, ao menos parcialmente?

Com o exame de tal problema a partir da observação de alguns casos voltados à história latino-americana e caribenha, pretende-se justamente valorizar procedimentos anteriores que podem ser hoje entendidos como ensaios de história global e que são capazes de subsidiar formas atuais dessa história menos pretensiosamente inovadoras e mais proveitosamente amparadas em tradições. Como pretendemos demonstrar neste artigo, a historiografia sobre a América Latina e o Caribe está recheada delas. Por essa razão, não faremos uma análise exaustiva, mas meramente exemplificadora. Para a seleção de tais exemplos, porém, e como logo se verá, buscou-se observar critérios coevos de relevância temática, densidade teórica e impacto historiográfico. Tampouco se trata de exemplos perfeitamente homogêneos ou coesos do ponto de vista da coerência analítica ou das intenções efetivas dos autores respectivos; mas simplesmente de esboços de agrupamentos que permitam a relativização dos afãs inovadores atuais que parecem obscurecer a história de uma história global, bem como limitar as potencialidades de seu exercício nos dias de hoje.

32 A tarefa de seleção de exemplos que possam fundamentar essa discussão se complica, desde o início, pelo reconhecimento de que muito do que se escreveu em termos do que poderíamos, hoje, considerar como história global, é de difícil classificação e agrupamento. Isso se deve não apenas ao fato de que, em geral, seus variados autores não se preocuparam em identificar-se como "globais", mas também e principalmente a que se trata de obras com objetivos muito distintos entre si, trabalhos concebidos e escritos em contextos muito variados. De certo modo, porém, tal reconhecimento contribui justamente para diminuir parte das pretensões à inovação dos atuais historiadores globais, pois aponta para uma quase naturalidade de se pensar a história do continente americano como histórias não exclusivamente nacionais e também como parte de histórias que não se limitam a ele. Não está aqui, nesse tipo de recorte, o começo de qualquer história global?

Lembremos rapidamente alguns casos iniciais. Posicionado no centro dos debates que subsidiariam o estabelecimento de uma historiografia nacional canônica na ainda relativamente recente República Argentina e no mesmo ano (1887) em que se publicava a quarta e definitiva edição de sua Historia de Belgrano y de la Independencia Argentina, Bartolomé Mitre começaria a dar à luz sua outra obra centrada em próceres independentistas rio-platenses: a Historia de San Martín y de la emancipación sudamericana (DEVOTO; PAGANO 2009; WASSERMAN 2008). Significativamente, e em meio a polêmicas que ora afastavam, ora sintonizavam seu autor em relação ao que outros já tinham proposto, aqui um herói de estatura nacional é tomado como protagonista de uma 
história que transcende à de sua nação para se tornar uma história continental. Esse procedimento é equiparável ao que, pouco depois (1895), faria também, a seu modo, Joaquim Nabuco. Em Balmaceda, o publicista brasileiro desenvolvia uma análise da guerra civil que ocorrera quatro anos antes no Chile e do papel nela desempenhado por seu presidente, mas com o olho no Brasil e em todo o continente americano. Para todos os efeitos, contudo, se queixava:

A América do Sul, seja-me lícito dizer de passagem, e sem aplicação ao Chile, não teve ainda um historiador; não existe esboço crítico completo da sua existência política; ninguém extraiu ainda do vasto material avulso enterrado em suas capitais longínquas um arcabouço de história. Não há nada escrito do ponto de vista universal (NABUCO 2008, p. 27). ${ }^{1}$

É possível concordar com Nabuco no tocante à ausência de uma perspectiva histórica universal da América; mas não há dúvidas de que, no final do século XIX, vários de seus historiadores pareciam ter em mente a necessidade de se pensar a história do continente como uma história para além dele.

Pouco mais de meio século após Nabuco, a lição fora devidamente aprendida: uma história da América como parte da história do mundo. Era o que praticaria, por exemplo, Antonello Gerbi, que em La disputa del Nuovo Mondo (1955) analisou um conjunto de elaborações intelectuais cujas múltiplas variações ao longo da história convergiriam, todas elas, para o reconhecimento de que a América (ou as Américas) integraram desde sempre uma mesma unidade histórica. Ou Edmundo O’Gorman, com sua La invención de América (1958), na qual a noção de "descobrimento" do continente, até então cara à imensa maioria de seus estudiosos, cedia lugar à de incorporação da América em uma visão de mundo europeia responsável, ela mesma, por ditar padrões longevos e inadequados de interpretação agora finalmente rompidos. E, finalmente, Sérgio Buarque de Holanda, cuja Visão do paraíso (1959) tomava a formação de imaginários coletivos em torno da colonização da América em uma perspectiva verdadeiramente global, ao mesmo tempo comparativa e integradora (GERBI 1996; HOLANDA 1992; O'GORMAN 1992).²

Os exemplos poderiam ser muitos. Até o momento, os poucos que oferecemos bastam para abrir um leque de possibilidades do qual surgem alguns agrupamentos de tendências que merecem ser observadas. No que segue deste artigo, iremos apresentar brevemente três delas que, ao longo do século $X X$, informaram parte de uma produção historiográfica relevante que, efetivamente, poder-se-ia classificar como história global.

\section{James, Williams e a escravidão negra no Caribe}

A primeira tendência localiza-se em obras sobre a escravidão negra no Caribe inspiradas pelo marxismo, e seus pioneiros foram Cyril Lionel Robert

\footnotetext{
${ }^{1}$ Para um amplo estudo acerca da trajetória política e intelectual deste autor, ver SALLES 2002.

2 A perspectiva comparativa e global de Sérgio Buarque de Holanda, em realidade, vinha de antes, de seu clássico Raízes do Brasil, editado inicialmente em 1936. Dentro de semelhante escopo, cabe inscrever a obra de Gilberto Freyre, bem mais conhecida pelo público anglo-saxão: ver, em especial, FREYRE 1933 (versão em inglês: FREYRE 1987), e FREYRE 1959.
} 
James e Eric Williams, historiadores e políticos nascidos em Trinidad e Tobago. Tendo por foco, respectivamente, os impérios francês e britânico em sua base caribenha, seus livros publicados na virada da década de 1930 para a de 1940 trouxeram grande novidade em relação às formas anteriores de escrita da história da escravidão negra nas Américas, justamente por inscreverem-na em processos históricos mais amplos do hemisfério ocidental.

The Black Jacobins (1938), de James, continha já em seu título o enunciado de uma perspectiva abrangente. O autor analisou a história da revolução escrava de São Domingos em suas múltiplas intersecções com a dinâmica econômica, social e política europeia. Para ele, a exploração sistemática da colônia caribenha ao longo do século XVIII dera origem a poderosos grupos mercantis sediados em Nantes, Bordéus e Marselha; ciosos do monopólio sobre as colônias, tais grupos entraram em frequentes choques com os planters residentes no Caribe em torno do problema do contrabando e do comércio com os rivais da França, notadamente mercadores britânicos e norte-americanos. Na esfera local, a posição dos senhores de escravos residentes se via desafiada tanto por conflitos com o grupo dos colonos brancos pobres como por aqueles com a cada vez mais pujante comunidade de negros e mulatos livres da ilha. James apontou como todas essas tensões eram conformadas pela estrutura do colonialismo europeu no Caribe e pela dinâmica da competição interimperial. A rivalidade crescente entre a burguesia francesa e uma fração da burguesia britânica portadora de um novo projeto imperial com foco nas Índias Orientais e impulsionado pela crítica à escravidão negra fez o conflito entre suas respectivas Coroas crescer em direção à escala global. Após as guerras dos Sete Anos (1756-1763) e a de independência dos Estados Unidos (1776-1783), São Domingos - a principal rival das West Indies britânicas - tornou-se o lócus do próximo e decisivo round da disputa entre as duas potências. Nas palavras de James, "tais eram as forças que na década anterior à Revolução Francesa conectavam São Domingos à economia de três continentes e aos conflitos sociais e políticos daquela fértil era" (1989, p. 55).

Ao eclodir o levante escravo de 1791, os eventos do Caribe se revelariam cruciais para o curso da revolução na própria Europa, posicionando a questão colonial no cerne dos destinos políticos do Ocidente. ${ }^{3}$ Mais importante, porém, teria sido o lugar ocupado por grupos subalternos - os trabalhadores escravizados de - São Domingos - que, aqui, emergem como sujeito histórico coletivo a partir da própria dinâmica de funcionamento da exploração colonial. ${ }^{4}$ Se o título do livro - no qual a expressão "jacobinos negros" evocava a associação entre as

\footnotetext{
${ }_{3}^{3}$ James sugere, por exemplo, que o fracasso das intervenções militares francesa e britânica em São Domingos e a vitória dos ex-escravos comandados por Touissant L'Ouverture foram determinantes para impedir que a Grã-Bretanha atacasse o território continental francês entre 1793 e 1799.

${ }^{4} \mathrm{Em}$ uma célebre passagem, James sustentou que os escravos das plantations americanas estavam mais próximos do proletariado industrial moderno do que do campesinato tradicional, e que isso teria favorecido sua organização revolucionária: "the slaves worked on the land, and, like revolutionary peasants everywhere, they aimed at the extermination of their oppressors. But working and living together in gangs of hundreds on the huge sugar-factories which covered the North Plain, they were closer to a modern proletarian than any group of workers in existence at the time, and the rising was, therefore, a thoroughly prepared and organized mass movement" (JAMES 1989, p. 84-86).
} 
massas de Paris e os escravos negros das colônias - era impreciso do ponto de vista histórico, não deixava de expressar bem o tipo de abordagem trazida por James, para todos os efeitos uma história global vista de baixo.

A obra de Eric Williams pode ser considerada em estrita articulação com a de James, já que, em seu livro clássico de 1944, Williams voltou-se ao exame da escravidão negra no Caribe britânico valendo-se de um modelo explicativo bem próximo ao de Black Jacobins. Para comprová-lo, basta mirarmos alguns elementos da elaboração de Capitalism and Slavery, nascido de uma tese de doutorado defendida na Universidade de Oxford no mesmo ano da publicação do livro de James. Na década de 1930, a chamada "escola imperial britânica" dominava a escrita da história do colonialismo e da escravidão caribenha, servindo de muitos modos à legitimação do presente do Império Britânico. ${ }^{5}$ Por isso, escrever a história a partir de pressupostos alternativos fazia parte da campanha pela própria dissolução do império.

O trabalho de Williams, ao focar fatores econômicos na abolição do tráfico transatlântico de escravos e da escravidão negra no império britânico, afastou-se dos cânones de interpretação da "escola imperial". Tratava-se de uma obra que seguia à risca um padrão consagrado de tese acadêmica em História, sobretudo no que se refere ao rigoroso encadeamento cronológico da narrativa e ao domínio exaustivo que demonstrava sobre a documentação. A tese concentrou-se no período de 1783 a 1838, examinando o declínio da importância econômica das Índias Ocidentais para o Império Britânico após a Revolução Americana; o crescimento do tráfico negreiro e da escravidão em São Domingos; as tentativas de conquista britânica da colônia francesa durante o curso da revolução escrava; o impacto do fracasso dessa tentativa para a abolição do tráfico transatlântico em 1807; a decadência da produção açucareira do Caribe britânico em face dos demais competidores mundiais; as ameaças das rebeliões escravas de Barbados, Demerara e Jamaica e seus impactos sobre a opinião pública britânica; e os limites colocados pelo monopólio das Índias Ocidentais para o avanço das forças capitalistas na metrópole.

O malogro em publicá-la rapidamente e a dificuldade em encontrar um posto de trabalho no sistema universitário britânico levaram Williams a se mudar para os Estados Unidos, onde, na Universidade de Howard, encontraria condições estimulantes para a revisão do plano original de seu trabalho. O elemento mais importante para a reconfiguração do projeto tinha sido dado antes, com o aparecimento, justamente, da obra de Cyril Lionel Robert James. A interpretação de Williams sobre as relações contraditórias entre capitalismo e escravidão foi diretamente retirada de Black Jacobins; além disso, Williams adicionaria ao seu livro, finalmente publicado em 1944, três eixos ausentes na tese de 1938: os relativos à compreensão da escravidão negra como um fenômeno econômico, em uma elaboração da ideia do racismo funcional colocado a serviço da exploração de classe; à centralidade do complexo escravista atlântico para a formação do capitalismo industrial na Inglaterra; e ao papel da resistência escrava para a

\footnotetext{
Sobre a escola imperial britânica, veja-se, com proveito, LOUIS 1999.
} 
derrubada da escravidão - tema desenhado mas pouco desenvolvido na tese. Além disso, Williams inspirou-se no tom político de James e em sua escrita direta, ácida e envolvente, que expressava a concepção de que a prática do ofício do historiador deveria ser uma atividade eminentemente política (WILLIAMS 1944). ${ }^{6}$

James e Wiliams estiveram, assim, entre os primeiros historiadores a conectar a formação do capitalismo europeu à escravização em massa dos africanos no Novo Mundo. Com eles, a escravidão negra foi alçada à gênese do mundo moderno, abrindo caminho para toda uma linhagem de investigações sobre o problema do desenvolvimento desigual na arena da economia mundial capitalista. Foram também dos primeiros a apresentar um modelo de análise que encarava os processos históricos desenrolados em diferentes partes do espaço atlântico como constituindo uma unidade orgânica, com eventos do Velho Mundo (a Europa e a África) e do Novo Mundo (a América) em um jogo de determinações recíprocas.

\section{Braudel e os Annales}

A perspectiva global de James e Williams seria muito inspiradora para historiadores e cientistas sociais voltados, nas décadas de 1960 e 1970, para o passado colonial da América Latina. Outra fonte de inspiração viria de uma matriz bem distinta, mas fundada em experiências e investigações na região que se iniciaram também a partir dos anos 1930: os trabalhos vinculados à chamada segunda geração da escola dos Annales, capitaneada por Fernand 36 Braudel. Como se sabe, o projeto coletivo desse notável grupo de historiadores foi vincado por uma preocupação comum em apreender os objetos investigados por meio de uma perspectiva abrangente e totalizadora da história, com forte diálogo com a geografia, a demografia e a economia. Outra marca distintiva do grupo estaria na atenção à dialética dos tempos históricos - na formulação braudeliana, a percepção dos distintos ritmos temporais de estruturas, conjunturas e acontecimentos. ${ }^{7}$

Vale destacar um momento mais especificamente "latino-americano" das elaborações de Braudel. Sua formulação pioneira apareceu na primeira edição de O Mediterrâneo, defendida como tese de doutorado na Sorbonne em 1947 e na qual a equação sobre os diferentes ritmos do(s) tempo(s) histórico(s) se deu por meio de um esquema tripartido concernente a "um tempo geográfico", "um tempo social" e "um tempo individual" (BRAUDEL 1983). Se ainda não se tratava da formulação final oferecida em seu ensaio sobre a "longa duração", de 1958, esse esquema continha em si todo um programa de pesquisa que moveria historiadores associados aos Annales por cerca de um quarto de século. Como Braudel chegou a essa formulação? Na passagem de uma tese originalmente concebida nos anos 1920 dentro do campo da história diplomática

\footnotetext{
${ }^{6}$ Para as diferenças entre a tese e o livro, ver TEMPERLY 1987 e DARITY JR. 1997. Para uma exploração recente das proximidades e distanciamentos entre os dois historiadores e políticos, ver GARCÍA MUÑIZ 2011. 7 Os escritos programáticos de Fernand Braudel foram reunidos em BRAUDEL 1959. O ensaio sobre a "Ionga duração", publicado originalmente em 1958, recebeu recentemente nova tradução para o inglês a cargo de WALLERSTEIN 2009.
} 
para o seu resultado final muito distinto vinte anos depois, e que traria um novo modo de compreender as relações entre tempo e espaço na escrita da história (focadas em complexos histórico-geográficos de longa duração), dois episódios foram cruciais para Braudel: o contato intelectual com a primeira geração dos Annales, sobretudo com Lucien Febvre; e sua experiência como docente da Universidade de São Paulo (Brasil), entre 1935 e 1937. Nos últimos anos de sua vida, Braudel afirmaria: "eu me tornei inteligente indo ao Brasil". Evidentemente, tal frase pode eventualmente ser lida em tom de nostalgia pessoal; mas, como já foi demonstrado por especialistas na obra de Braudel, ela parece traduzir a importância da experiência brasileira - como experiência global - para a elaboração de suas noções acerca do(s) tempo(s) histórico(s) (AGUIRRE 2003; LIMA 2009).

Durante seu cativeiro na Segunda Guerra Mundial, Braudel pensou em escrever uma tese secundária (então uma exigência do sistema universitário francês para a obtenção do doutorado) sobre o Brasil do século XVI, mas não o fez. No entanto, em sua curta experiência como professor da Sorbonne, entre 1945 e 1946, ministrou um curso sobre a América Latina na virada do século XVIII para o XIX, atraindo alunos como Frédéric Mauro e Pierre Chaunu, que logo se envolveram com a perspectiva analítica de Braudel (DAIX 1999). Na década seguinte e em estreito diálogo com Braudel, Chaunu e Mauro elaborariam trabalhos matriciais para a compreensão da história colonial dos impérios de Portugal e da Espanha no contexto atlântico mais amplo, escorados no modelo geo-histórico inicialmente proposto para o Mediterrâneo. No caso dos muitos volumes da obra de Chaunu (cuja parte estatística foi preparada em parceria com sua esposa, Huguette) sobre as relações comerciais entre Sevilha e a América espanhola, a história era desenvolvida como meio de apreensão de invariâncias do tempo estrutural, bem como de suas inflexões. No caso de Mauro, a consideração de um espaço geográfico (o Atlântico Sul) comandado em suas margens por um único poder europeu resultaria em uma análise das formas de produção impostas pelos portugueses e do papel estrutural da escravidão negra para o funcionamento de todo um sistema imperial que, como bem sabia o autor, fora desde sempre um sistema também global (CHAUNU; CHAUNU 19551959; MAURO 1960).

Às perspectivas abertas por Braudel deve-se acrescentar, também, a obra do historiador português Vitorino Magalhães Godinho. Sua trajetória acadêmica começou em Portugal, no começo da década de 1940, com uma investigação sobre a expansão ultramarina portuguesa no século XV; diante das dificuldades de exercício de seu ofício impostas pelo salazarismo, Godinho buscou refúgio na França, onde encontrou guarida no grupo dos Annales. A partir de 1949, além de publicar considerável número de ensaios e de exercer a docência na Universidade de São Paulo (ocupando o mesmo posto que fora de Braudel na década de 1930), Godinho preparou sua monumental obra, Os descobrimentos e a economia mundial, apresentada na França em 1969 como tese de Doctorat d'État e cuja versão definitiva apareceria em português no começo da década de 1980. Trata-se de um exemplo eloquente de história da era inaugurada pelos 
descobrimentos marítimos europeus como história global ${ }^{8}$ que evitava uma perspectiva eurocêntrica ao avaliar cuidadosamente as múltiplas e complexas relações econômicas, sociais e culturais entre as forças do capital europeu em seu movimento de expansão pelas várias áreas do globo e os povos com os quais entraram em contato na Ásia, na África e na América. De particular relevo é a conceituação do que o autor denominou "complexos histórico-geográficos" da economia mundial entre os séculos XII e XVII, cuja moldura teórica lhe permitiu aquilatar como a história da América foi produzida pela história global e, reversivamente, a produziu (GODINHO 1981-1983). ${ }^{9}$

Ainda no campo da escola dos Annales, pode-se destacar um livro composto a partir das anotações de um curso ministrado na Sorbonne em fins da década de 1960, da lavra de autor reconhecidamente marxista e especialista na história da Catalunha moderna. Oro y moneda en la historia, de Pierre Vilar, apareceu inicialmente em espanhol em 1969 (VILAR 1980). Na obra, o autor caracteriza o lugar ocupado pela América Latina na história global da exploração do ouro e da prata e de suas implicações em termos de preços e valores de moeda no mundo moderno. Nela, temos o exame da exploração da prata em Potosí (ecologia, formas de trabalho envolvidas, implicações em termos de organização da sociedade indígena e de articulações mercantis regionais) e de suas relações com a expansão econômica global da segunda metade do século XVI, bem como uma análise da história financeira mundial dos séculos XVII, XVIII, XIX e começos do XX. Ao integrar os amplos circuitos de produção e circulação da prata e do ouro, Vilar tratou de forma substantiva as implicações, na longa duração, da integração da América ao espaço econômico europeu, antecipando muitos dos debates que mobilizam as discussões correntes sobre o papel dos metais preciosos americanos na conformação do capitalismo mundial. ${ }^{10}$

Por fim, não convém olvidar a magnus opus de Fernand Braudel, que pode ser considerada como uma espécie de síntese de boa parte desse esforço coletivo de pesquisa em perspectiva global até aqui sumariado. Em sua trilogia sobre a história do capitalismo entre os séculos XV e XVIII, as Américas portuguesa e espanhola e o Caribe desempenham papel de destaque como espaços privilegiados de atuação do capital europeu e, portanto, de "descolamento" do Ocidente em relação ao mundo asiático (fartamente tratado na obra) (BRAUDEL 1996). Mesmo os autores que, de alguma forma, associavam-se aos Annales mas que, após a publicação de Civilização material, economia e capitalismo, séculos XVI-XVIII (entre 1966 e 1979), recusaram-se a encampar a conceituação braudeliana de "economia-mundo capitalista" - caso de Ruggiero Romano, em seu livro sobre as conjunturas opostas da crise do século XVII na Europa e na América espanhola (ROMANO 1993) -, não deixaram de, em muitos momentos, valorizar

\footnotetext{
8 Poderíamos citar, da mesma época, a obra de síntese de outro importante historiador, afastado dos cânones teóricos e metodológicos dos Annales, mas tão praticante de uma história global quanto Magalhães Godinho: BOXER 1969. Igualmente importante, mas a partir da história da Espanha: ELLIOTT 1970. Na mesma linha de preocupações e de escopo igualmente global, ainda que de uma geração posterior: PAGDEN 1982.

${ }_{9}^{9}$ Ver, também, os bons esclarecimentos sobre a obra desse historiador apresentados por TOMICH 2005.

10 Nesse sentido, os trabalhos inovadores de FLYNN; GIRALDEZ (1995 e 1996) muito ganhariam com um engajamento mais próximo às implicações da perspectiva analítica de Pierre Vilar.
} 
parte do arsenal teórico e metodológico desenvolvido pela escola e aplicá-lo em suas próprias investigações, o que só fez crescer, de modos variados, o prestígio de enfoques globais para a escrita da história da América Latina.

\section{A teoria da dependência e o sistema-mundo}

Uma terceira vertente de estudos globais voltados à história da América Latina e do Caribe nasceu no campo do debate econômico sobre a problemática do desenvolvimento e do subdesenvolvimento na região. Se algumas de suas raízes podem ser buscadas em autores e obras como os que apresentamos anteriormente, ela teve também características específicas, pois foi elaborada como resposta direta (do ponto de vista latino-americano) ao contexto político e econômico mundial da Grande Depressão. Com efeito, foi como gestor público na Argentina nas décadas de 1920 e 1930 que Raúl Prebisch iniciou uma revisão crítica dos pressupostos da economia clássica e neoclássica sobre o comércio internacional, notadamente da teoria das vantagens comparativas. Em trabalhos concebidos como de circulação restrita, escritos quando era gerente geral do Banco Central daquele país e sob a inspiração de Keynes, Prebisch propôs, talvez pela primeira vez, categorias como as de centro e periferia do sistema econômico mundial. Ao ser nomeado secretário executivo da Comissão Econômica para a América Latina (CEPAL), em 1948, Prebisch ampliaria o escopo teórico de sua obra com a formulação mais acabada de tais categorias, bem como das ideias de deterioração dos termos de troca, de estruturas duais na periferia e de desenvolvimento para dentro. Tais ferramentas analíticas, para serem devidamente exploradas, exigiam um mergulho na história da América Latina e do Caribe embasado em uma perspectiva verdadeiramente global (DOSMAN 2011).

É provável que a expressão máxima do emprego das categorias prebischianas para o estudo da história da região resida na obra do economista brasileiro Celso Furtado, outro destacado membro do quadro da CEPAL. Em sua obra mais importante, Formação econômica do Brasil (1959), Furtado inscreveu a análise da colonização ibérica do Novo Mundo dentro do contexto mais amplo da expansão comercial europeia, ressaltando a assimetria de fundo entre o que chamou "colônias de exploração" americanas (constituídas por zonas tropicais como o nordeste do Brasil, as Antilhas, as colônias do sul dos Estados Unidos, e por zonas de mineração como Nova Espanha e Peru, Minas Gerais) e "colônias de povoamento" (as do norte da América britânica continental). ${ }^{11}$ A comparação sistemática entre essas duas experiências coloniais distintas indicava, para Furtado, o fundamento da cisão histórica entre o desenvolvimento econômico dos Estados Unidos e o subdesenvolvimento da América Latina e do Caribe. Nas "colônias de exploração", o trabalho compulsório (africano ou indígena), a alta mercantilização de uma produção destinada ao centro do capitalismo global, a concentração da propriedade fundiária e da renda e a atrofia dos

\footnotetext{
${ }_{11}$ Tais expressões não foram cunhadas por Furtado, tendo sido empregadas anteriormente por uma grande diversidade de autores por diferentes motivos. Entre eles, ressalta-se o político marxista Karl Kaustky, que, no ensaio Socialism and Colonial Policy, de 1907, propôs as categorias "work colonies" e "exploitation colonies" em termos bem próximos aos que seriam posteriormente desenvolvidos pelos cientistas sociais latino-americanos.
} 
setores voltados ao mercado interno (marcados por baixa capitalização e produtividade) - suas características básicas - teriam travado o crescimento econômico autossustentável fundado na industrialização, a verdadeira marca do desenvolvimento. Já as "colônias de povoamento", caracterizadas pelo trabalho livre, por uma economia voltada às necessidades locais e por uma distribuição mais equilibrada da terra e da renda, teriam tomado o caminho de "desenvolvimento para dentro", baseadas que estavam em fortes mercados internos (FURTADO 1959; 1970).

Da crítica à eficácia do modelo da CEPAL para explicar a mudança histórica - e, também, para superar a condição de subdesenvolvimento após duas décadas de conversão de sua aplicação como política econômica em diversos países da América Latina - nasceria a chamada teoria da dependência. Ainda que desenvolvida basicamente por sociólogos e economistas menos afeitos ao trabalho de investigação empírica do que os historiadores, não se pode desconsiderar a relevância, em particular, de dois trabalhos dessa perspectiva para o estudo da história da América Latina nos quadros de uma história global: primeiro, o de Fernando Henrique Cardoso e Enzo Falleto, no qual a análise das relações de classe na periferia do sistema mundial capitalista foi convertida em elemento chave para a compreensão das barreiras historicamente impostas ao desenvolvimento; segundo, o de André Gunder Frank, que destacava a exploração sistemática das zonas satélites do sistema capitalista do século XVI ao século $X X$, supostamente voltadas em sua totalidade à acumulação de capitais HO nos centros metropolitanos, como o verdadeiro obstáculo ao desenvolvimento, independentemente das formas de produção e de trabalho empregadas na periferia (CARDOSO; FALETTO 1969; FRANK 1967).

Cardoso e Falleto e Gunder Frank tiveram grande impacto na comunidade dos historiadores, tanto por reações positivas quanto por negativas. No que se refere aos estímulos positivos, Stanley e Barbara Stein publicaram, em 1970, um pequeno volume no qual examinavam as distinções entre o processo histórico da colonização espanhola e portuguesa (com metrópoles ainda presas às estruturas feudais) e o da colonização britânica e francesa, com metrópoles em franco processo de transição para o capitalismo industrial. Com esse livro, o casal iniciou um programa de investigação ambicioso, ainda em andamento, sobre a inscrição da Nova Espanha nos quadros do capitalismo global (STEIN; STEIN 1970; 2000; 2003; 2009). Também no plano da incorporação de pressupostos da teoria da dependência para a investigação histórica, pode-se mencionar o trabalho do historiador argentino Tulio Halperín Donghi, que, em dois livros publicados no intervalo de duas décadas (1968 e 1985), examinou de forma integrada as trajetórias históricas da América portuguesa e da espanhola, com ênfase em articulações entre base material e dinâmica social e política de cada zona, em uma longa duração a incluir história colonial e história nacional (HALPERÍN 1968; 1985). Na historiografia brasileira, o impactante livro de Fernando Novais (1979) sobre o colonialismo português na virada do século XVIII para o XIX mostra uma incorporação teórica simultânea do modelo explicativo de Eric Williams sobre as relações contraditórias entre capitalismo e 
escravidão, da concepção braudeliana sobre a pluralidade dos tempos históricos e das formulações dependentistas sobre as relações entre centro e periferia do sistema mundial. Sua finalidade foi a de analisar as bases sobre as quais teria se assentado a exploração europeia sobre o Novo Mundo (com foco nas relações entre Portugal e Brasil) e os mecanismos geradores da crise de dissolução de um sistema colonial de abrangência global (NOVAIS 1979). ${ }^{12}$

No que concerne às reações negativas, sobrelevam-se os trabalhos de Ernesto Laclau e Ciro Flamarion Cardoso, que criticaram duramente os paradigmas cepalino e dependentista e seus desdobramentos historiográficos, ressaltando a necessidade de se conferir prioridade analítica às relações de produção coloniais, isto é, à história da América em seus graus de autonomia em relação ao restante do mundo. Cabe registrar que essa perspectiva, se por um lado concedia primazia explicativa à face "interna" do mundo colonial (concepção rejeitada pelos praticantes de uma concepção sistêmica de história, para os quais não há "internalidade" ou "externalidade" entre fenômenos, apenas sua integração), por outro ressaltava a necessidade de comparações abrangentes entre as diferentes formações históricas da América Latina e do Caribe, permanecendo, assim, aberta a abordagens de caráter global. É o que se observa, por exemplo, com a elaboração da categoria de "modo de produção escravista colonial" por Ciro Cardoso, que se fundou em uma ampla apreensão das diversas sociedades escravistas do continente americano, valendo-se igualmente de um diálogo cerrado com as tradições historiográficas dos autores marxistas caribenhos e da segunda geração da escola dos Annales (CARDOSO 1975; 1979; GORENDER 1978; LACLAU 1971).

Os debates críticos em torno dessas três heranças (marxismo, Annales, dependentismo) forneceram o contexto intelectual para a elaboração da perspectiva de análise dos sistemas-mundo. Como efeito, é possível identificar claramente os aportes de Eric Williams, Fernand Braudel, Raul Prebisch e André Gunder Frank na influente obra de Immanuel Wallerstein, cujo primeiro volume de 1974 seria seguido por outros três (WALLERSTEIN 1974; 1980; 1989; 2011). Seguindo passos desses autores, porém com um acabamento teórico e metodológico bastante original, Wallerstein apresentou fortes argumentos a respeito do papel crucial que a incorporação das Américas ao espaço da economia-mundo capitalista europeia teria tido para a gênese e desenvolvimento do chamado "sistema-mundo moderno". Ironicamente, no entanto, uma das mais duras reações ao modelo de história global por ele proposto seria justamente a de um importante latinoamericanista, cuja crítica contribuiria significativamente para erodir durante um bom tempo a atratividade de perspectivas analíticas globais para a guilda dos historiadores da América Latina e do Caribe. ${ }^{13}$ Noutras palavras, tendo-se em

\footnotetext{
12 No tocante a essa abrangência, Novais reconheceu explicitamente sua dívida intelectual para com autores como Celso Furtado e, antes dele, Caio Prado Júnior, que em seu Formação do Brasil contemporâneo (1942), afirmara: "Em suma e no essencial, todos os grandes acontecimentos desta era, que se convencionou com razão chamar 'dos descobrimentos', articulam-se num conjunto que não é senão um capítulo da história do comércio europeu. Tudo que se passa são incidentes da imensa empresa comercial a que se dedicam os países da Europa a partir do século XV, e que Ihes alargará o horizonte pelo Oceano afora" (PRADO JR 1989, p.22). ${ }_{13}$ Ver, a respeito, a troca de artigos entre Stern e Wallerstein (STERN 1988a; 1988b; WALLERSTEIN 1988).
} 
vista o que foi predominante na escrita da história da região nos anos 1990-2000, a polêmica entre Steve Stern e Immanuel Wallerstein nas páginas da American Historical Review pareceu ter se encerrado com o triunfo de análises históricas formuladas em termos preponderantemente locais e de curta duração - à feição do que reivindicara Stern - por sobre a valorização da história da América Latina como componente ativo de uma história mundial - o que pareceria natural a partir de uma revisão (parcial) das propostas de Wallerstein.

\section{Perspectivas atuais}

É possível afirmar que, não obstante uma considerável perda de terreno, a história da América Latina e do Caribe produzida sob uma perspectiva global jamais desapareceu por completo e até mesmo continuou a render bons frutos na virada do século XX para o XXI. Avaliar essa produção não é a intenção destas páginas, cujos objetivos foram tão somente anotar como em várias importantes obras que remontam a trajetórias historiográficas já de muitas décadas foram praticadas histórias globais sob diversos pontos de vista; da mesma forma, sugerir que parte da atual historiografia latino-americanista não tem sido indiferente a tais esforços anteriores que, não obstante, ainda mereceriam maior atenção.

A historiografia sobre a escravidão negra, por exemplo, tem demonstrado grande dinamismo ao perquirir as conexões econômicas, sociais e culturais entre a África e o Novo Mundo, em um crescente número de publicações inspiradas em matrizes teóricas e metodológicas bastante diversas. ${ }^{14}$ No entanto, cremos que uma abordagem verdadeiramente global, que examine as mútuas e complexas determinações entre as unidades geográficas latino-americanas e caribenhas submetidas a escrutínio e as forças mais amplas do colonialismo e do capitalismo modernos, ainda carece de maior frequência e consistência. Assim, vale destacar que dois dos mais inovadores trabalhos relativamente recentes sobre a escravidão negra nas Américas em perspectiva hemisférica partiram justamente de diálogos diretos com Eric Williams e Cyril Lionel Robert James.

Em livro de 1988, Robin Blackburn examinou o conjunto dos espaços escravistas americanos de forma articulada, lançando luz sobre as proximidades e os distanciamentos de suas trajetórias no contexto da crise geral da escravidão negra e do colonialismo europeu durante a passagem do século XVIII para o XIX, com destaque para o entendimento das relações entre o processo de abolição do tráfico negreiro e da escravidão no Caribe britânico e a revolução escrava no Caribe francês (dois temas ainda frequentemente tratados de forma isolada). Posteriormente, Blackburn propôs as categorias escravidão barroca e escravidão comercial como chaves para compreender as disjunções entre a escravidão ibérica e a escravidão francesa/britânica, atrelando cada qual às distintas posições que suas respectivas metrópoles ocupavam no concerto europeu. Por fim, em volume mais recente, o autor propôs um modelo geral 
para o que chamou de "três idades" da escravidão do Novo Mundo (escravidão barroca, escravidão comercial, nova escravidão oitocentista), bastante promissor para apreender a historicidade das relações entre capitalismo e escravidão em longa duração (BLACKBURN 1988; 1997; 2011; TOMICH 2004). Também buscando inspiração em Williams e James, mas seguindo trilhas da perspectiva analítica de Wallerstein, Dale Tomich apresentou, em ensaio de 1988, a categoria segunda escravidão para dar conta das profundas articulações entre a escravidão cubana, a brasileira e a norte-americana dentro dos quadros da economiamundo industrial do século XIX. A categoria tem estimulado um bom número de publicações sobre a escravidão no continente americano a posicionarem-no em uma moldura analítica efetivamente global (BERBEL; MARQUESE; PARRON 2010; LAGO 2012; NOWARA 2011; TOMICH 2004).

No que se refere à herança da escola dos Annales, Serge Gruzinski, especialista em história colonial de Nova Espanha, publicou em 2004 um ambicioso livro no qual conceituou o período da União das Coroas Ibéricas (1580-1640) como o primeiro esforço genuíno de mundialização sob o signo de valores e práticas ocidentais. Vemos, aqui, uma tentativa em compatibilizar os rumos da virada da história em direção à antropologia, que tanto marcou a historiografia posterior à década de 1970, com os questionamentos totalizadores que haviam motivado anteriormente historiadores como Pierre Chaunu, Fréderic Mauro, Vitorino Magalhães Godinho e, sobretudo, Fernand Braudel (GRUZINSKI 2004; GRUZINSKI; SUBRAHMANYAN 2007; SUBRAHMANYAN 1993). ${ }^{15}$ Por outro lado, as potencialidades não completamente exploradas da perspectiva geo-histórica dos Annales foram retomadas pelo historiador brasileiro Luiz Felipe de Alencastro ao analisar o papel crucial do tráfico negreiro no Atlântico Sul para a formação brasileira. Mais do que uma perspectiva de história atlântica, temos aqui um exercício que coloca os movimentos econômicos e políticos do Brasil e da África em um jogo de múltiplas determinações moduladas pelo quadro mais amplo das disputas coloniais europeias (ALENCASTRO 2000). ${ }^{16}$

Em diálogo crítico com a perspectiva do sistema-mundo, porém tomando-Ihe de empréstimo o constructo analítico das "cadeias mercantis", Steven Topik, Carlos Marichal e Zephir Frank editaram em 2006 uma importante coletânea de ensaios sobre o papel das mercadorias produzidas na América Latina para a conformação das redes da economia mundial, do início do século XVI ao final do século XX. É interessante registrar que, apesar de reiterarem algumas das críticas feitas àquela perspectiva (inclusive a de Steve Stern), os resultados a que os autores chegaram ao examinar as várias cadeias de mercadorias (prata, índigo, cochonilha, tabaco, café, açúcar, cacau, banana, guano, borracha, henequém, cocaína) que atavam a economia da América Latina à economia mundial parecem compatíveis com os postulados originais do moderno sistema-mundial (TOPIK;

\footnotetext{
${ }^{15}$ Há de se destacar que, para além de Magalhães Godinho, a historiografia de Portugal desde muito esteve vocacionada para a prática de uma história global; afinal, haveria outro modo de se escrever a história de seu império? Para um destacado representante dessa historiografia, ver, dentre outros, THOMAZ 1994.

${ }_{16}$ Assim sendo, em termos da abrangência dada a seu objeto, tal autor se insere em uma tradição, já citada anteriormente, que remonta a Fernando Novais e Celso Furtado, embora com eles não dialogue explicitamente.
} 
MARICHAL; FRANK 2006). Seja como for, a fecunda agenda apresentada pelo volume oferece um amplo leque de possibilidades àqueles que pretendem explorar os vínculos entre as formas de produção presentes no mundo americano e as engrenagens da economia global.

Podemos, agora, retornar a nosso ponto de partida, isto é, ao momento em que a multiplicação de Estados e de sociedades nacionais surgidos com o fim dos impérios ibéricos na América impôs uma percepção coeva de que a história daquele momento só poderia ser compreendida em uma perspectiva global. A historiografia dos processos de independência na América, como já apontado anteriormente, jamais abandonou por completo essa premissa, que, aliás, parece bem consolidada na atualidade, como atesta uma numerosíssima produção. ${ }^{17}$ Para todos os efeitos, continuam fortemente presentes inquietações como as que moveram o historiador francês Jacques Godechot há mais de cinquenta anos, cujas propostas em torno de uma história de "revoluções atlânticas" representaram um pioneiro esforço de conciliar a perspectiva dos agentes históricos com a dos seus historiadores. ${ }^{18}$

Em meio a esse panorama, emergem temáticas dinâmicas e multifacetadas, como a responsável por um dos mais criativos e fecundos esforços dessa historiografia, a reunir centenas de especialistas de diversos países em torno de uma perquirição integrada da história de linguagens e conceitos políticos utilizados na América Latina e no mundo ibérico entre as décadas finais do século XVIII e as iniciais do XIX, sob coordenação do historiador espanhol Javier Fernández Sebastián (2009). A originalidade de tal empreitada, assim como seus eloquentes resultados até o momento disseminados em grande quantidade de trabalhos acadêmicos -, sugere um potencial de pesquisa ainda pouco explorado: a articulação de dimensões político-intelectuais, discursivas e simbólicas com dimensões materiais (economia, fluxos comerciais) das sociedades latino-americanas da época. Tal potencial poderia valer-se amplamente da recuperação de algumas das formas de história global aqui apontadas.

Como se vê, há muitas e muitas formas de se valorizar e de se praticar abordagens de história global a partir da América Latina. Retomando as queixosas palavras de Joaquim Nabuco escritas há mais de cem anos e mencionadas ao início destas páginas, poder-se-ia dizer, neste século XXI no qual a humanidade (e sua pequena parcela de historiadores) está mais globalizada do que nunca, que o continente americano já dispõe de uma história escrita "do ponto de vista universal"? É possível que sim. No entanto, tal resposta depende da realização

\footnotetext{
17 Uma amostragem desse consenso pode ser obtida nas entrevistas com historiadores contidas em CHUST 2010. 18 De início, Godechot desenvolveu a ideia em colaboração com o historiador norte-americano Robert Palmer, do que resultou um célebre paper apresentado ao International Congress of Historical Sciences de Roma, em 1955; contudo, diferentemente de Palmer - cuja obra magna seria The Age of the Democratic Revolution: a Political History of Europe and America -, Godechot conferiu grande ênfase ao papel da América ibérica e do Caribe em seu modelo de interpretação (GODECHOT 1956). Uma vertente crítica das elaborações de Palmer e Godechot resultaria na proposta em torno de uma "Era das Revoluções"; as formulações de seu principal difusor dariam grande ênfase ao desenvolvimento do capitalismo em escala mundial (HOBSBAWM 1962). Um paradigmático exemplo atual de exercício de história global altamente profissionalizada mas pouco disposta a dialogar com tradições anteriores como as aqui apontadas é a de Armitage e Subrahmanyam (2010).
} 
de uma crítica historiográfica pormenorizada, exaustiva e propositiva que os historiadores latino-americanistas ainda não parecem ter realizado.

\section{Referências bibliográficas}

AGUIRRE ROJAS, Carlos Antonio. Braudel, o mundo e o Brasil. São Paulo: Cortez Editora, 2003.

ALENCASTRO, Luiz Felipe de. O trato dos viventes: formação do Brasil no Atlântico sul. São Paulo: Companhia das Letras, 2000.

ARMITAGE, David; SUBRAHMANYAM, Sanjay (eds.). The Age of Revolutions in Global Context c. 1760-1840. London: Palgrave, 2010.

BERBEL, Márcia; MARQUESE, Rafael; PARRON, Tâmis. Escravidão e Política: Brasil e Cuba, c. 1790-1850. São Paulo: Hucitec, 2010.

BOXER, Charles. The Portuguese Seaborne Empire, 1415-1825. London: Longman, 1969.

BLACKBURN, Robin. The Overthrow of Colonial Slavery, 1776-1848. London: Verso, 1988.

The Making of the New World Slavery from the Baroque to the Modern, 1492-1800. London: Verso, 1997.

. The American Crucible: Slavery, Emancipation and Human Rights. London: Verso, 2011.

BRAUDEL, Fernand. Écrits sur I'Histoire. Paris: Flamarion, 1959.

O Mediterrâneo e o Mundo Mediterrânico na Época de Felipe II.

São Paulo: Martins Fontes, 1983 [1949]. 2 v.

. Civilização Material, Economia e Capitalismo, séculos XV-XVIII. São Paulo: Martins Fontes, 1996 [1979]. 3 v.

CARDOSO, Ciro Flamarion Santana. Sobre os modos de produção coloniais da América. In: SANTIAGO, Theo (org.). América Colonial. Rio de Janeiro: Pallas, 1975, p. 61-132.

Agricultura, escravidão e capitalismo. Petrópolis: Vozes, 1979.

CARDOSO, Fernando Henrique; FALETTO, Enzo. Dependencia y desarrollo en América Latina. Mexico: Siglo XXI, 1969.

CHAUNU, Pierre; CHAUNU, Huguette. Seville et I'Atlantique (1504-1650). Paris: S.E.V.P.E.N., 1955-1959. 8 v.

CHUST, Manuel (ed.). Las independencias iberoamericanas en su laberinto: controversias, cuestiones, interpretaciones. Valencia: PUV, 2010.

DAIX, Pierre. Fernand Braudel: uma biografia. Rio de Janeiro: Record, 1999. DARITY JR., William. Eric Williams and Slavery: A West Indian Viewpoint? Callaloo, v. 20, n. 4, p. 800-816, autumn 1997. 
DEVOTO, Fernando; PAGANO, Nora. Historia de la historiografía argentina. Buenos Aires: Sudamericana, 2009.

DOSMAN, Edgar J. Raúl Prebisch (1901-1986): a construção da América Latina e do Terceiro Mundo. Rio de Janeiro: Contraponto, 2011.

ELLIOTT, John H. The Old World and the New, 1492-1650. Cambridge: Cambridge University Press, 1970.

FERNÁNDEZ SEBASTIÁN, Javier (dir.). Diccionario político y social del mundo iberoamericano. Madrid: Fundación Carolina/Sociedad Estatal de Conmemoraciones Culturales/Centro de Estudios Políticos y Constitucionales, 2009.

FLYNN, Dennis; GIRALDEZ, Arturo Giraldez. China and the Spanish Empire. Revista de História Económica, v. 14, n. 2, p.309-338, 1996. . Born with a "Silver Spoon": The Origin of World Trade in 1571.

Journal of World History, v. 6, n. 2, p. 201-221, 1995.

FRANK, André Gunder. Capitalism and Underdevelopment in Latin America. New York: Monthly Review Press, 1967.

FREYRE, Gilberto. Casa Grande \& Senzala. Rio de Janeiro: José Olympio, 1933. The Master and the Slaves: A Study in Development of the Brazilian Civilization. Berkeley: The University of California Press, 1987.

New World in the Tropics: the Culture of Modern Brazil. New York: Alfred Knopf, 1959.

FURTADO, Celso. Formação Econômica do Brasil. São Paulo: Companhia das Letras, 2009 [1959].

Economic Development of Latin America: Historical Background and Contemporary Problems. Cambridge: Cambridge University Press, 1970.

GARCÍA MUÑIZ, Humberto. Eric Williams y C. R. L. James: simbiosis intelectual y contrapunteo ideológico. In: WILLIAMS, Eric. El negro en el Caribe y otros textos. La Habana: Editorial Casa de las Américas, 2011, p.419450.

GERBI, Antonello. O Novo Mundo. História de uma polêmica, 1750-1900. São Paulo: Companhia das Letras, 1996.

GODECHOT, Jacques. La Grande Nation. Paris: Aubier, 1956.

GODINHO, Vitorino Magalhães. Os Descobrimentos e a economia mundial. Lisboa: Editorial Presença, 1981-1983. 4 v.

GORENDER, Jacob. O escravismo colonial. São Paulo: Ática, 1978.

GRUZINSKI, Serge. Les Quatre Partes du Monde: Histoire d'une mondialisation. Paris: Éditions de la Martinière, 2004. 
; SUBRAHMANYAM, Sanjay. Holding the World in Balance: the Connected Histories of the Iberian Overseas Empires, 1500-1640. The American Historical Review, v. 112, n. 5, p. 1359-1385, dec. 2007.

HALPERÍN DONGHI, Tulio. Storia dell'America Latina. Torino: Einaudi, 1968. . Reforma y disolución de los imperios ibéricos, 1750-1850. Madrid: Alianza Editorial, 1985.

HOBSBAWM, Eric J. The Age of Revolutions, 1789-1848. London: Weidenfeld and Nicolson, 1962.

HOLANDA, Sérgio Buarque de. Raízes do Brasil. Rio de Janeiro: José Olympio, 1936.

. Visão do Paraíso: os motivos edênicos no descobrimento e colonização do Brasil. Edição revisada. São Paulo: Brasiliense, 1992.

JAMES, Cyril Lionel Robert. The Black Jacobins: Toussaint L'Ouverture and the San Domingo Revolution. 2a edição. New York: Vintage, 1989.

KAUTSKY, Karl. Socialism and Colonial Policy. London: Athol Books, 1975 [1907].

LACLAU, Ernesto. Feudalism and Capitalism in Latin America. New Left Review, 67, p.19-38, 1971.

LAGO, Enrico Dal. American Slavery, Atlantic Slavery, and Beyond: the U.S. 'Peculiar Institution' in International Perspective. Boulder: Paradigm Publishers, 2012.

LIMA, Luís Corrêa. Fernand Braudel e o Brasil: vivência e brasilianismo (19351945). São Paulo: Edusp, 2009.

LOUIS, W. Roger. Introduction. In: WINKS, Robin W.; LOW, Alaine (eds.). The Oxford History of the British Empire. Oxford: Oxford University Press, 1999 , p. 1-42. v. 5.

MAURO, Frédéric. Le Portugal, le Brésil et I'Atlantique au XVIIe siècle (1570-1670). Paris: S.E.V.P.E.N., 1960. 2 v.

NABUCO, Joaquim. Balmaceda. 4a edição. São Paulo: Cosac Naify, 2008 [1895].

NOVAIS, Fernando A. Portugal e Brasil na crise do Antigo Sistema Colonial (1777-1808). São Paulo: Hucitec, 1979.

NOWARA, Christopher Schmidt. Slavery, Freedom, and Abolition in Latin America and the Atlantic World. Albuquerque: University of New Mexico Press, 2011.

O'GORMAN, Edmundo. A invenção da América. São Paulo: Ed. Unesp, 1992.

PAGDEN, Anthony. The Fall of Natural Man: The American Indian and the origins of comparative anthropology. Cambridge: Cambridge University Press, 1982. 
PALMER, Robert. The Age of the Democratic Revolution: a Political History of Europe and America, 1760-1800. Princeton: Princeton University Press, 1959-1964.

PRADO JR., Caio Prado. Formação do Brasil contemporâneo. $21^{\text {a }}$ edição. São Paulo: Brasiliense, 1989 [1942].

REIS, João José; GOMES, Flávio dos Santos; CARVALHO, Marcus J. M. O Alufá Rufino: tráfico, escravidão e liberdade no Atlântico negro (c. 1822-1853). São Paulo: Companhia das Letras, 2010.

ROMANO, Ruggiero. Coyunturas opuestas: la crisis del siglo XVII en Europa e Hispanoamérica. México: Fondo de Cultura Económica, 1993.

ROMERO, J. L.; ROMERO, L. A. (orgs.). Pensamiento político de la emancipación (1790-1825). Caracas: Ayaucho, 1997.

SALLES, Ricardo. Joaquim Nabuco, um Pensador do Império. Rio de Janeiro: Topbooks, 2002.

SCOTT, Rebecca J.; HÉBRARD, Jean M. Freedom Papers: An Atlantic Odyssey in the Age of Emancipation. Cambridge MA: Harvard University Press, 2012.

STEIN, Stanley J.; STEIN, Barbara H. The Colonial Heritage of Latin America. New York, Oxford Universtity Press, 1970. of Early Modern Europe. Baltimore: The John Hopkins University Press, 2000.

Apogee of Empire: Spain and New Spain in the Age of Charles III, 1759-1789. Baltimore: The John Hopkins University Press, 2003.

; Edge of Crisis: War and Trade in the Spanish Atlantic, 17891808. Baltimore: The John Hopkins University Press, 2009.

STERN, Steve J. Feudalism, Capitalism, and the World-System in the Perspective of Latin America and the Caribbean. American Historical Review, v. 93, n. 4, p. 829-872, 1988.

. Feudalism, Capitalism, and the World-System in the Perspective of Latin America and the Caribbean: 'Ever More Solitary'. American Historical Review, v. 93, n. 4, p. 886-897, 1988.

SUBRAHMANYAM, Sanjay. The Portuguese Empire in Asia, 1500-1700: a Political and Economic History. London and New York: Longman, 1993.

SWEET, James H. Domingos Alvares, African Healing, and the Intellectual History of the Atlantic World. Chapel Hill: The University of North Carolina Press, 2013.

TEMPERLEY, Howard. Eric Williams and Abolition: the Birth of a New Orthodoxy. In: SOLOW, Barbara; ENGERMAN, Stanley (ed.). British Capitalism and 
Caribbean Slavery: the Legacy of Eric Williams. Cambridge: Cambridge University Press, 1987, p. 229-57.

THOMAZ, Luiz Filipe. De Ceuta a Timor. Lisboa: Difel, 1994.

TOMICH, Dale. Vitorino Magalhães Godinho. Atlantic History, World History.

Review: A Journal of the Fernand Braudel Center, vol.XXVIII, n.4, pp.305-12, 2005.

. Through the Prism of Slavery: Labor, Capital, and World Economy. Boulder CO: Rowman \& Littlefield Publ., 2004.

TOPIK, Steven; MARICHAL, Carlos; FRANK, Zephir (ed.). Latin American Commodity Chains and the Building of the World Economy, 15002000. Durham: Duke University Press, 2006.

VILAR, Pierre. Ouro e moeda na História (1450-1920). Rio de Janeiro: Paz \& Terra, 1980 [1969].

WALLERSTEIN, Immanuel. Fernand Braudel, "History and the Social Sciences: The Long Durée". In: Review: A Journal of the Fernand Braudel Center, v.XXXII, n.2, pp.171-204, 2009.

The Modern World System I: Capitalist Agriculture and the Origins of the European World-Economy in the Sixteenth Century. New York: Academic Press, 1974.

The Modern World-System II: Mercantilism and the Consolidation of the European World-Economy, 1600-1750. New York: Academic Press, 1980.

The Modern World-System III: The Second Era of Great Expansion of the Capitalist World-Economy, 1730-1840s. New York: Academic Press, 1989.

. The Modern World-System IV: Centrist Liberalism Triumphant, 1789-1914. Berkeley: University of California Press, 2011.

. Feudalism, Capitalism, and the World-System in the Perspective of Latin America and the Caribbean: Comments on Stern's Critical Tests. American Historical Review, v. 93, n. 4, p. 873-885, oct. 1988.

WASSERMAN, Fabio. Entre Clio y la Polis: conocimiento histórico y representaciones del pasado en el Río de la Plata (1830-1860). Buenos Aires: Teseo, 2008.

WILLIAMS, Eric. Capitalism and Slavery. Chapel Hill: The University of North Carolina Press, 1994. 